\title{
Article
}

\section{Ethanol-based proliposome delivery systems of paclitaxel for in vitro application against brain cancer cells}

\author{
Najlah, M, Jain, M, Wan, Ka-Wai, Ahmed, Waqar, Albed Alhnan, \\ Mohamed, Phoenix, David Andrew, Taylor, K and Elhissi, Adbelbary \\ Available at http://clok.uclan.ac.uk/16746/ \\ Najlah, M, Jain, M, Wan, Ka-Wai, Ahmed, Waqar ORCID: 0000-0003-4152-5172, \\ Albed Alhnan, Mohamed, Phoenix, David Andrew, Taylor, K and Elhissi, \\ Adbelbary (2016) Ethanol-based proliposome delivery systems of paclitaxel \\ for in vitro application against brain cancer cells. Journal of Liposome \\ Research . pp. 1-12. ISSN 0898-2104
}

It is advisable to refer to the publisher's version if you intend to cite from the work. http://dx.doi.org/10.1080/08982104.2016.1259628

For more information about UCLan's research in this area go to http://www.uclan.ac.uk/researchgroups/ and search for <name of research Group>.

For information about Research generally at UCLan please go to http://www.uclan.ac.uk/research/

All outputs in CLoK are protected by Intellectual Property Rights law, including Copyright law. Copyright, IPR and Moral Rights for the works on this site are retained by the individual authors and/or other copyright owners. Terms and conditions for use of this material are defined in the policies page.

\section{CLoK}

Central Lancashire online Knowledge www.clok.uclan.ac.uk

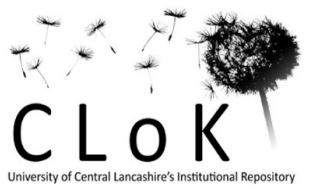




\section{Ethanol-Based Proliposome Delivery Systems of Paclitaxel for In Vitro Application Against Brain Cancer Cells}

*1 Mohammad Najlah, ${ }^{2}$ Mohit Jain, ${ }^{2}$ Ka-Wai Wan, ${ }^{2}$ Waqar Ahmed,

${ }^{2}$ Mohamed Albed Alhnan, ${ }^{3}$ David A. Phoenix, ${ }^{4}$ Kevin M.G. Taylor, **5 Abdelbary Elhissi

${ }^{1}$ Faculty of Medical Science, Anglia Ruskin University, Bishops Hall Lane, Chelmsford CM1 1SQ, United Kingdom

${ }^{2}$ Institute of Nanotechnology and Bioengineering, School of Pharmacy and Biomedical Sciences, and School of Medicine and Dentistry, University of Central Lancashire, Preston PR1 2HE, United Kingdom

${ }^{3}$ Office of the Vice Chancellor, London South Bank University, 103 Borough Road, London SE1 OAA, United Kingdom

${ }^{4}$ Department of Pharmaceutics, UCL-School of Pharmacy, 29-39 Brunswick Square, London WC1N 1AX, United Kingdom

${ }^{5}$ Pharmaceutical Sciences Section, College of Pharmacy, Qatar University, P.O. Box 2713, Doha, Qatar

**Corresponding author 1:

Dr. Abdelbary Elhissi

Pharmaceutical Sciences Section

College of Pharmacy, Qatar University

P.O. Box 2713

Doha, Qatar

T: +974 44035632

E: aelhissi@qu.edu.qa or aelhissi@yahoo.com 
*Corresponding author 2:

Dr. Mohammad Najlah

Faculty of Medical Science, Anglia Ruskin University

Bishops Hall Lane

Chelmsford CM1 1SQ

United Kingdom

T: +44 (0)1245 684682

E: mohammad.najlah@anglia.ac.uk or m_najlah@yahoo.co.uk 


\section{Ethanol-Based Proliposome Delivery Systems of Paclitaxel for In Vitro Application Against Brain Cancer Cells}

In this study the anticancer activity of paclitaxel-loaded nano-liposomes on glioma cell lines was investigated. Soya phosphatidylcholine: cholesterol (SPC:Chol), hydrogenated soya phosphatidylcholine: cholesterol (HSPC:Chol) or dipalmitoylphosphatidylcholine: cholesterol (DPPC:Chol) in 1:1 mole ratio were used to prepare ethanol-based proliposomes. Following hydration of proliposomes, the size of resulting vesicles was subsequently reduced to nanometre scale via probe-sonication. The resulting formulations were characterised in terms of size, zeta potential and morphology of the vesicles, and entrapment efficiency of paclitaxel (PX) as well as the final $\mathrm{pH}$ of the preparations. DPPC-liposomes entrapped 35-92\% of PX compared to 27-74\% and 25-60\% entrapped by liposomes made from SPC and HSPC formulations respectively, depending on drug concentration. The entrapment efficiency of liposomes was dependent on the lipid bilayer properties and ability of PX to modify surface charge of the vesicles. In vitro cytotoxicity studies revealed that PX-liposome formulations were more selective at inhibiting the malignant cells. The cytotoxicity of PX-liposomes was dependent on their drug entrapment efficiency. This study has shown PXliposomes generated from proliposomes have selective activity against glioma cell lines, and the synthetic DPPC phospholipid was most suitable for maximised drug entrapment and highest activity against the malignant cells in vitro.

Keywords: proliposome; entrapment efficiency; cytotoxicity; phospholipids; paclitaxel; cell culture 


\section{Introduction}

Paclitaxel (PX) has been reported to demonstrate a significant anticancer activity against ovarian carcinoma, head and neck cancers, breast cancer, lung cancer and AIDS related Kaposi's sarcoma (Rowinsky and Donehower, 1995). Despite its promising efficacy, the clinical use of paclitaxel is limited by its poor water-solubility as well as low cellular permeability (Wani et al., 1971, Panchagnula, 1998, Singla et al., 2002, Yoshizawa et al., 2014). For clinical administration of paclitaxel, the drug is dissolved in Cremophor ${ }^{\circledR}$ EL (Poly-oxyethylated castor oil) and ethanol (50:50 v/v) followed by dilution by 5-20 times before parenteral injection; the marketed formulation with this vehicle system is Taxol ${ }^{\circledR}$. Unfortunately, Cremophor EL causes serious toxic effects such as nephrotoxicity, hypersensitivity reactions, neurotoxicity, laboured breathing, hypotension and lethargy (Singla et al., 2002). Therefore, replacing Cremophor ${ }^{\circledR}$ EL by a biocompatible formulation that can also increase aqueous solubility and improve therapeutic efficacy of the drug is highly needed (Kadam et al., 2014). Abraxane ${ }^{\circledR}$ is an FDA approved nanomedicine formulation of paclitaxel attached with albumin nanoparticles (Garber, 2004). Clinical investigations have demonstrated that Abraxane ${ }^{\circledR}$ can offer $14 \%$ higher response rate and $33 \%$ greater tumour penetration than Taxol ${ }^{\circledR}$ (Garber, 2004). However, obtaining large quantities of human albumin is expensive, thus designing alternative nanomedicines that are safe and economically affordable is highly desirable.

Liposomal-based formulations have been suggested as 'non-toxic' nanomedicines, owing to the great similarity of the liposomal phospholipids with biological membranes; this makes liposomes highly biocompatible and biodegradable (Crosasso et al., 2000, Koudelka and Turánek, 2012). Incorporation of PX in liposomes can reduce the drug toxicity to normal tissues and eliminate the hypersensitivity reactions caused by Cremophor EL 
vehicle. Liposomes also reduce the dose-limiting toxicity of PX by significant elevation of the maximum tolerated dose (MTD) of the drug (Sharma et al., 1993, Cabanes et al., 1998, Fetterly and Straubinger, 2003).

Intracranial administration of liposomal paclitaxel in rat brain tumor model has shown to increase the life span in the animals to up to $40 \%$ compared to cremophor EL and ethanol mixture formulations (Zhou et al., 2010). Lipusu® (Luye Pharma Group) is a paclitaxel liposomal formulation that has recently been commercialized and recommended for the treatment of breast, ovarian and non-small cell lung cancer (Koudelka and Turánek, 2012, Wang et al., 2013).

A major limitation of liposomes is their poor stability, owing to oxidation and hydrolysis of the phospholipids. Proliposome technologies such as particulate-based proliposomes (Payne et al., 1986a, Payne et al., 1986b) and ethanol (solvent)-based proliposomes (Perrett et al., 1991) have been advocated to overcome the instability manifestations of liposomes and provide convenient and economic options when compared to spray-drying or freeze-drying of liposomes. Ethanol-based proliposomes are ethanolic lipid solutions which, depending on the hydration procedure, generate oligolamellar liposomes (Perrett et al., 1991) or multilamellar vesicles (Turánek et al., 1997). Proliposomes can also offer a feasible approach for manufacturing liposome precursors on a large scale,(Gala et al., 2015) thus overcoming the instability problems (liability of phospholipid to hydrolysis, oxidation and subsequent leakage of entrapped drug), high costs and unsuitability of conventional thin-film made liposomes for large scale production (Kensil and Dennis, 1981, Grit et al., 1989). 
Liposomes prepared by ethanol-based proliposome method have been shown to provide high entrapment efficiency for hydrophilic drugs. The entrapment efficiency ranged from 60 to $80 \%$ depending on the composition of phospholipid (Perrett et al., 1991) and 30 to $85 \%$ depending on the hydration protocol of the proliposomes (Turánek et al., 1997, Elhissi et al., 2006). Noteworthy, that hydration temperature employed was important at influencing the entrapment efficiency as high temperature $\left(60^{\circ} \mathrm{C}\right)$ provided an effective entrapment (approx. 80\%) rather than at low temperature $\left(20^{\circ} \mathrm{C}\right)$ where the entrapment was around 50\% (Turánek et al., 1997). Hydrophobic drugs may also have high entrapment efficiencies in these liposomes. Entrapment efficiencies of 93 to $98 \%$ have been reported for levonorgestrel depending on type of alcohol employed in the formulation (Deo et al., 1997). In this study, we have introduced paclitaxel-loaded liposomes prepared via the ethanol-based proliposome technology using various lipid compositions. Physicochemical properties of formulations such as size, size distribution, zeta potential, $\mathrm{pH}$, vesicle morphology and drug entrapment efficiency were studied. Moreover, the cytotoxicity of the formulations on grade IV glioma (U87-MG) and normal glial (SVG-P12) cell lines was investigated.

\section{Methods}

\section{Materials}

Soya phosphatidylcholine (SPC; Lipoid S-100), hydrogenated phosphatidylcholine (HSPC; Phospholipon 90H) and dipalmitoyl phosphatidylcholine (DPPC) were obtained from Lipoid, Switzerland. EMEM (Eagle's minimum essential medium), non-essential 
amino acid solution and L-glutamine (cell culture tested, 99.0 - 101.0 \%) were purchased from Lonza, Switzerland. Trypsin-EDTA solution, ethanol (absolute and 70\%), 96-well plates (sterile with lids), $50 \mathrm{ml}$ centrifuge tubes (sterile), tissue culture flask $75 \mathrm{~cm}^{2}$ (sterile) and serological pipettes (sterile) were obtained from Fisher Scientific, UK. Cholesterol (Chol; $\geq 99 \%$ ), glass vials $(15 \mathrm{ml})$, poly-L-lysine (PLL) hydrobromide (molecular weight 30,000-70,000), dextran (molecular weight 5,000 approx.), Dimethyl sulfoxide (DMSO), thiazolyl blue tetrazolium bromide, Fetal bovine serum (FBS), Phosphate buffered saline (PBS) tablets, Trypan blue solution $(0.4 \%$ liquid, sterile filtered), Syringe filters $(0.2$ and $0.45 \mu \mathrm{m})$, syringe needles and sterile pipette tip boxes were all purchased from Sigma Aldrich, UK. Human glioblastome cell line (U87-MG) and Human glial cell line (SVG-P12) were obtained from European collection of cell cultures, UK. Paclitaxel (PX) was purchased from ChemieTek, USA.

\section{Preparation of Liposomes}

The lipid phase (phospholipid: Chol, 1:1 mole ratio) (50 mg) was dissolved in absolute ethanol $(75 \mu \mathrm{l})$ at $70^{\circ} \mathrm{C}$ (water bath) for $1 \mathrm{~min}$ within a $15 \mathrm{ml}$ glass vial. Paclitaxel was then added in the ethanolic solution to produce a range of concentrations in the subsequent aqueous dispersion $(0.1,0.3,0.5$ and $1 \mathrm{mg}$ per $\mathrm{ml}$ of the final liposomal dispersion). Aqueous (water) phase $(10 \mathrm{ml})$, significantly above the $\mathrm{T}_{\mathrm{m}}$ of the lipid was added immediately to avoid lipid phase solidification. Liposomes were generated upon vigorous hand shaking and vortex mixing (Fisons Whirlimixer, UK) for $4 \mathrm{~min}$. Liposomal formulations were then kept for annealing above the $\mathrm{T}_{\mathrm{m}}$ of the lipids for $2 \mathrm{~h}$ followed by size, zeta potential measurements and electron microscopy studies. 


\section{Size Reduction of Liposomes}

Liposome dispersions $(10 \mathrm{ml})$ were probe-sonicated (Sonics Vibra-cell-CV33, USA) at the highest frequency for a maximum of $10 \mathrm{~min}$ with intermittent cooling to avoid excessive heating of the liposomes. The resultant dispersion (except for those of the entrapment determination) was centrifuged (Jouan Robotics A-14, France) at 10,000 rpm $(9,200 \mathrm{~g})$ for $2 \mathrm{~min}$ to remove the titanium particles leached from the probe of the sonicator.

\section{Laser Diffraction Size Analysis for Liposomes Before Size Reduction}

Laser diffraction technique was used for size analysis of liposomes. The measurements were performed using the Malvern Mastersizer 2000 (Malvern instruments Ltd., UK). This was carried out by addition of $70 \mathrm{ml}$ of deionised water to the cone dispersion unit (Hydro2000 SM, UK) of the instrument. Size and size distribution were presented as the volume median diameter (VMD) (50\% undersize) and Span respectively. Span $=(90 \%$ undersize $-10 \%$ undersize) / VMD.

\section{Photon Correlation Spectroscopy (PCS) Analysis After Size Reduction}

Photon correlation spectroscopy (PCS) technique relies on the Brownian motion of the particles using the Zetasizer instrument (Zetasizer nano, Malvern Instruments Ltd., UK). The size and polydispersity of the sonicated liposomes (in the supernatant; i.e. following removal of titanium particles) were analyzed by recording the hydrodynamic diameter $\left(\mathrm{Z}_{\text {average }}\right)$ and polydispersity index (PI) respectively using the Zetasizer instrument (Zetasizer nano, Malvern Instruments Ltd., UK).

\section{Determination of Drug Entrapment Efficiency}

Entrapment efficiency of PX was determined by adapting the separation methods previously used by Kumar et al (2001) and Gala et al (Gala et al., 2015). Liposome 
suspension was passed through syringe filters $(0.45 \mu \mathrm{m})$ at least three times. The filter was then washed with HPLC water until the solution ran clear. Then, the filter was placed in absolute ethanol and paclitaxel was extracted. The extracted fraction was collected to determine the proportion of un-entrapped drug using Dionex Ultimate 3000 UHPLC with BetaBasic column 18 particle size $5 \mu \mathrm{m}$, pore size 150A, 150mm L x 4.6mm I.D. Mobile phase; acetonitrile: water:methanol $(55: 45: 5)$ at wavelength $227 \mathrm{~nm}$, retention time was 5.6 min. This amount was subtracted from the total amount of PX in the liposomes to calculate the amount of entrapped drug. The solubility of paclitaxel in water is less than $0.1 \mu \mathrm{g} / \mathrm{mL}$ (Konno et al., 2003), therefore, the amount of the drug dissolved in water during hydration was ignored. The entrapment efficiency (EE) of paclitaxel (PX) in liposomes was calculated using the following equation:

$$
E E(\%)=\frac{\text { Amount of PX entrapped }}{\text { Total amount of PX in liposome formulation }} \times 100
$$

\section{Cytotoxicity Study (MTT Assay)}

The U87-MG cells (grade IV glioma, passage 13) and SVG-P12 (glial cells, passage 7) were seeded at $1 \times 10^{5}$ cells/well in 96-well plates and maintained at $37^{\circ} \mathrm{C}$ in an atmosphere of $5 \% \mathrm{CO}_{2}$ and $95 \%$ relative humidity in Eagle's minimum essential medium (EMEM) supplemented with 10\% FBS, $1 \mathrm{mM}$ sodium pyruvate, $2 \mathrm{mM}$ L-glutamine and $0.1 \mathrm{mM}$ non-essential amino acids. Prior to assay, loaded liposomal formulations of 1 $\mathrm{mg} / \mathrm{ml}$ were filtered through a $0.4 \mu \mathrm{m}$ sterile syringe filters to remove unloaded paclitaxel. Considering the loading efficiency (Figure 5), filtered formulations were used as stocks diluted by media to yield 1, 2.5, 5, 25, 50, 250, 500, $1500 \mathrm{nM}$ of loaded paclitaxel.

After $24 \mathrm{~h}$ of incubation, the cells were washed in PBS solution, and $200 \mu \mathrm{l}$ of medium containing tested formulations each at range of concentrations was 
added (traces of DMSO (up to $0.3 \%$ ) were used to solubilise free PX in warm medium at $\left.37^{\circ} \mathrm{C}\right)$. After $72 \mathrm{~h}$ of incubation at $37 \mathrm{oC}, 20 \mu \mathrm{l}$ of $3-(4,5-$ dimethythiazole-2-yl)-2,5-diphenyltetrazolium bromide (MTT) solution (5 $\mathrm{mg} / \mathrm{ml}$ ) was added and cells incubated for a further $5 \mathrm{~h}$. Medium was removed, and $100 \mu$ l dimethylsulfoxide (DMSO) was added and incubated for further $30 \mathrm{~min}$ at $37 \mathrm{oC}$. Then, the optical density at $570 \mathrm{~nm}$ was measured (Tecan GENios Plus, Switzerland). The level of colour development in the control wells (containing only medium) was assumed to indicate $100 \%$ viability). The $\mathrm{IC}_{50}$ values (i.e. concentration resulting in $50 \%$ inhibition of cell growth) of the liposomes and paclitaxel were calculated graphically from the cell viability curves obtained by considering the absorbance of the media containing cells as $100 \%$ (Yang et al., 2007).

\section{Statistical Analysis}

Statistical significance was measured using the one-way analysis of variance (ANOVA) and student's $t$-tests as appropriate. All values were expressed as the mean \pm standard deviation. Values of $\mathrm{P}<0.05$ were regarded as significantly different.

\section{Results and Discussion}

\section{Size Analysis and Microscopic Morphology of Liposomes Before Sonication}

The influence of paclitaxel concentration and phospholipid composition on size distribution of the liposomes generated from ethanol-based proliposomes was investigated. Figure 1a shows the effect of paclitaxel concentration on the VMD of the formulated liposomes. The VMD of SPC-liposomes containing PX at $0.5 \mathrm{mg} / \mathrm{ml}(3.78 \pm$ $0.08 \mu \mathrm{m})$ and $1 \mathrm{mg} / \mathrm{ml}(3.83 \pm 0.09 \mu \mathrm{m})$ concentrations were larger than VMD of 
paclitaxel-free SPC-liposomes $(3.12 \pm 0.07 \mu \mathrm{m})(\mathrm{P}<0.05)$. However, the VMD of PXSPC-liposomes containing low PX concentration showed no significant difference when compared to that of PX-free SPC-liposomes $(\mathrm{P}>0.05)$. This suggests that the VMD of SPC-liposomes was increased by increasing drug concentration $(0.5$ and $1 \mathrm{mg} / \mathrm{ml})$ but not at lower PX concentrations $(0.1$ and $0.3 \mathrm{mg} / \mathrm{ml})$.

The VMDs of HSPC-liposomes containing PX were higher than that of drugfree HSPC-liposomes $(\mathrm{P}<0.05)$ (Figure 1a). Moreover, continuous increase in the size of HSPC-liposomes was observed as the concentration of PX was increased. Similarly, the VMD of all PX-DPPC-liposomes were significantly larger than drug-free DPPC-liposomes $(\mathrm{P}<0.05)$. Figure 1a shows that HSPCliposome size was almost doubled because of drug inclusion at the maximum concentration of $1 \mathrm{mg} / \mathrm{ml}$ within formulation. The VMD of all PX-DPPCliposomes increased by increasing paclitaxel concentration but not as high as that observed with PX-HSPC-liposomes (Figure 1a).

The VMD measurements of HSPC-based liposomes were higher than those of the corresponding DPPC-based liposomes $(\mathrm{P}<0.05)$. Amongst the phospholipids used, PX concentration was most influential to the size of vesicles made from HSPC:Chol (1:1). This is possibly attributed to the higher hydrophobicity of the longer acyl chains in HSPC phospholipid and repulsive interactions between water molecules at the interface, causing the vesicles to aggregate (Zhao and Feng, 2004, Zhao and Feng, 2005, Zhao et al., 2007). Size distribution of liposomes was represented by the measurement of Span, a term introduced by Malvern Instruments Ltd to express the polydispersity of particles. In general, no effect was seen on the Span of liposome formulations when PX was included, and the Span values for all formulations 
were around 2 (Figure 1b). The only exception was the Span of liposomes made from SPC:Chol $(1: 1)$ which increased $(\mathrm{P}<0.05)$ by inclusion of 0.1 $\mathrm{mg} / \mathrm{ml}$ PX. However, no further increase of SPC-made liposomes was observed by inclusion of higher drug concentrations. Drug concentration did not affect the Span of HSPC-liposomes or DPPC liposomes $(\mathrm{P}>0.05$; Figure $1 b)$.

TEM studies have shown that liposomes prior to probe-sonication were multilamellar vesicles (MLVs) and that was independent of drug concentration or lipid composition (images not shown). This agrees with our previous publication of liposomes prepared using the ethanol-based proliposome technology (Elhissi et al., 2006). Studies by other investigators have shown that liposomes generated from ethanol-based proliposomes were oligolamellar (Perrett et al., 1991) or multilamellar (Turánek et al., 1997).

\section{Size Analysis of Liposomes After Sonication}

Size of liposomes was reduced aiming to convert multilamellar vesicles (MLVs) into small unilamellar vesicles (SUVs) having a size range around $100 \mathrm{~nm}$. After probe sonication, the size of liposomes was decreased by approximately $95 \%$ or more (compared to size of initial MLVs), regardless of formulation (Figure 1a and Figure 2a). This indicates that drug inclusion and lipid composition did not retard size reduction and hence MLVs were successfully fragmented into nano-liposomes (100-200 nm) (Figure 2a). Moreover, liposomes made from HSPC:Chol (1:1) had larger size than liposomes made from DPPC:Chol (1:1) or SPC:Chol (1:1). These results correlate with TEM images (Figure 1S) for the $1 \mathrm{mg} / \mathrm{ml}$ PX concentration for SPC, HSPC and DPPC liposomes respectively. The TEM-images were taken after probe-sonication and clearly showed that vesicles were SUVs. The size of SPC, HSPC and DPPC liposomes according to TEM 
were approx. $125 \mathrm{~nm}, 175 \mathrm{~nm}$ and $155 \mathrm{~nm}$ respectively (Figure 1S). This indicates that size of sonicated vesicles was affected by lipid phase composition. Noteworthy, the effect of PX concentration on liposome size after sonication was minimal (Figure 2a).

The polydispersity index (PI) for all liposomes was found to be below 0.3 (Figure 2b), indicating that sonication has generated liposomes with relatively narrow size distribution, regardless of lipid type and drug concentration. However, an inconsistent effect of PX on polydispersity of the liposome vesicles was shown in Figure $2 \mathrm{~b}$ as it is difficult to correlate PX concentration with the PI value, regardless of phospholipid type. Overall, the low PI for all formulations indicates that the sonication time selected was appropriate and no further size reduction was required.

\section{Zeta Potential Analysis Before Sonication}

The zeta potential of all liposome formulations before sonication were in the negative range (Figure 3a). The average zeta potential of PX-free SPC-liposomes was $-1.82 \mathrm{mV} \pm$ 0.09 which increased to $-3.57 \mathrm{mV} \pm 0.28$ upon inclusion of $0.1 \mathrm{mg} / \mathrm{ml}$ paclitaxel $(\mathrm{P}<0.05)$. However, inclusion of higher concentrations of paclitaxel tended to reduce the charge intensity (Figure 3a). Overall, only a slight or no difference in zeta potential values were observed when drug-free liposomes were compared to liposomes having the highest PX concentration (i.e. $1 \mathrm{mg} / \mathrm{ml}$ ). It is possible that changes in zeta potential are related to changes in the VMD of liposomes (Ofir et al., 2007, Elhissi et al., 2013). Further research is required to understand why the negative zeta potential tended to increase at low drug concentration and revert to the original value upon inclusion of higher drug concentrations.

\section{Zeta Potential Analysis After Sonication}


The zeta potential of probe-sonicated liposomes was significantly lower than that of liposomes before size reduction, regardless of formulation. Furthermore, for SPC and HSPC-made liposomes, significant effects $(\mathrm{P}<0.05)$ of drug concentration on the zeta potential were observed (Figure 3b). For HSPC or SPC liposomes at low drug concentrations $(0.1$ or $0.3 \mathrm{mg} / \mathrm{ml})$, the zeta potential was approximate to neutrality (i.e. $0.00 \mathrm{mV}$ ). In contrast, DPPC-made vesicles showed more negative values. This may indicate that DPPC-made nano-liposomes are the most stable vesicles among the liposome formulations after sonication as the electrostatic repulsion between negatively charged DPPC vesicles may reduce aggregation (Howard and Levin, 2010).

The increased negativity of zeta potential for the PX-SPC and PX-HSPC liposomes as a result of increasing the drug concentration was only a slight trend. However, statistically significant differences between the formulations depending on the composition of phospholipid were observed (Figure 3b). Compared with liposomes prior to sonication (Figure 3a), the zeta potential of PX-free SPC-liposomes after sonication was almost neutral whereas the zeta potential of PX-SPC-liposomes containing the maximum drug concentration decreased in intensity by approximately $54 \%$ when compared to that of pre-sonicated PX-SPC liposomes (Figure 3a and b). This suggests that vesicle size has an effect on zeta potential values, agreeing with previous investigations (Howard and Levin, 2010).

\section{pH Measurement of Liposome Formulations}

The effect of drug concentration and lipid composition on the $\mathrm{pH}$ of liposomes was investigated. The $\mathrm{pH}$ of all SPC and HSPC liposomes was slightly acidic, while the $\mathrm{pH}$ 
of DPPC-liposomes was neutral to slightly basic (Figure 4). It is worth mentioning that the $\mathrm{pH}$ of formulations increased by increasing PX concentration. For SPC-liposomes, the $\mathrm{pH}$ of $\mathrm{PX}$-free liposomes was $6.06 \pm 0.01$ whereas the $\mathrm{pH}$ of liposomes having the maximum PX concentration was $6.72 \pm 0.02(\mathrm{P}<0.05)$. Similarly, the $\mathrm{pH}$ of $\mathrm{PX}$-free HSPC liposomes was $6.08 \pm 0.03$ while the $\mathrm{pH}$ of liposomes with maximum drug concentration was $6.84 \pm 0.2(\mathrm{P}<0.05)$. The $\mathrm{pH}$ of formulations was the highest for DPPC liposomes followed by HSPC and then SPC formulations. The pH of SPC and HSPCliposomes increased gradually by increasing the drug concentration $(\mathrm{P}<0.05)$. However, the $\mathrm{pH}$ of DPPC-liposomes remained the same until $0.5 \mathrm{mg} / \mathrm{ml} \mathrm{PX} \mathrm{concentration} \mathrm{with} \mathrm{no}$ significant difference. It can be concluded that differences in the $\mathrm{pH}$ of liposome formulations made using different lipids at similar PX concentrations were minimal. The $\mathrm{pH}$ of DPPC liposomes seems to be the closest to that of the physiological fluids ( $\mathrm{pH}$ 7.4). Thus, amongst the various phospholipids used in this study, DPPC seems to be the most appropriate excipient for manufacturing liposome delivery systems for the anticancer drug paclitaxel.

\section{Entrapment Efficiency of PX in Liposomes}

According to Figure 5a, the entrapment efficiency of PX decreased with the increase in drug concentration $(\mathrm{P}<0.05)$ and that was independent of phospholipid composition. For example, the entrapment efficiency of the drug in DPPC-liposomes was $92.3 \% \pm 2.7$ for $0.1 \mathrm{mg} / \mathrm{ml}$ and decreased by $57 \%$ using $1 \mathrm{mg} / \mathrm{ml}$ PX concentration $(35.3 \% \pm 1.8)$ $(\mathrm{P}<0.05)$. However, the entrapment efficiency in DPPC liposomes was generally higher than that in SPC and HSPC vesicles (Figure 5a). It is worth to mention that the difference in zeta potential with different PX concentrations may correlate with the different entrapment efficiencies using different lipid compositions. Figure $3 b$ clearly 
demonstrates that higher drug concentrations have conferred more negative surface charge on the DPPC liposomes. The ability of higher drug concentrations to exert that effect on SPC and HSPC vesicles was less, which correlates well with the entrapment efficiency findings. This gives a strong indication that the accommodation of paclitaxel within the liposome bilayers was responsible for the negative zeta potential values of DPPC vesicles.

Figure $5 \mathrm{~b}$ represents the amount of drug entrapped in $10 \mathrm{ml}$ of liposome formulation. The amount of PX entrapped in the formulations was dependent on the composition of phospholipid and drug concentration. However, in all formulations the amount of entrapped PX increased as the drug concentration was increased. However, this increase was not significant at high durg concentrations (i.e. formulations contain 5 and $10 \mathrm{mg}$ per $10 \mathrm{ml}$, figure $5 \mathrm{~b}$ ), displaying a plateau phase. This indicates that a maximum interaction between the drug and the phospholipid was reached and liposomes bilayers could not entrap more drug.

HSPC-liposomes had less entrapment efficiency than that of SPC and DPPCliposomes (Figure 5a) $(\mathrm{P}<0.05)$. The plateau phase was reached at HSPCliposomes formulation of $5 \mathrm{mg}$ PX loaded to $10 \mathrm{ml}$ but entrapped only $2 \mathrm{mg}$. The formulation could not entrap PX efficiently with the highest drug concentration as compared to that of lower drug concentrations investigated. Similarly, DPPC-liposomes displayed an increase in the entrapped PX by increasing its initial loaded concentrations; with the highest PX concentration (10 $\mathrm{mg} / 10 \mathrm{ml})$, the amount of drug entrapped was around $3.5 \mathrm{mg}$, which was higher than the maximum amount of drug entrapped in SPC or HSPC-made liposomes of the same loaded drug concentrations (figure 5b). According to 
Table 1 which shows the correlating mol\% entrapment values of PX, it is noticeable that entrapment findings for DPPC-liposomes $(4.2 \mathrm{~mol} \%$ at the maximum concentration) are slightly higher than those of the previously reported conventional liposomes (3 mol\% in general) (Koudelka and Turánek, 2012); this might be due to the difference in the preparation method in this study adopting ethanol-based proliposome technology. Accordingly, further investigation is suggested to establish any possible effect of traces of ethanol on the entrapment efficiency of PX in liposomes prepared by ethanolbased proliposome technology.

Previous studies suggested that the molecular interaction between PX and lipid was facilitated by including cholesterol in the DPPC/PX mixed bilayers; this made a more stable tertiary system of paclitaxel, cholesterol and DPPC (Zhao et al., 2007). Cholesterol containing liposomes are generally more rigid and stable than liposomes made from phospholipid alone. DPPC-liposomes possess two thermal transitions: a sharp acyl chain melting transition temperature of $42.3{ }^{\circ} \mathrm{C}$ and a pre-transition temperature of $35.4^{\circ} \mathrm{C}$ (Zhao et al., 2007). Incorporation of PX can eliminate the pre-transition temperature without changing the main phase transition temperature, leading to a flexible bilayer (Zhao et al., 2007). PX is localized in C1-C8 carbon atoms of the acyl chain i.e. in the outer hydrophobic bilayer zone of DPPC liposomes and binds to the carbon atoms of DPPC by its C13 side chain, which is hydrophobic due to the presence of two aromatic rings (Balasubramanian and Straubinger, 1994, Zhao et al., 2007).

It has also been found that the stability of PX in saturated phospholipids is dependent on the chain length, with DPPC (16:0), (number of carbons in the 
fatty acid chains and the degree of unsaturation), liposomes being more capable of entrapping higher proportions of paclitaxel than HSPC (18:0) liposomes (Zhao and Feng, 2004). The interaction between phospholipid and PX has been reported to be nonspecific and dependent on the hydrophobic binding or van der Waals forces. The stronger van der Waals interactions in the longer chain can hinder the movement of paclitaxel in the bilayers. This forms unstable systems when compared to phospholipids with shorter acyl chain (Zhao and Feng, 2004). This may explain the higher entrapment efficiency using DPPC (shorter chain) liposomes compared to HSPC vesicles. DPPC possesses a first-order phase transition, a transition between liquidexpanded and liquid-condensed states, whereas HSPC possess only liquidcondensed phase. This may be due to the higher hydrophobicity of longer acyl chain phospholipids (of HSPC) and the lower possibility to exist in the tilted liquid-expanded state due to repulsive interactions between water molecules at the interface (Zhao and Feng, 2004, Zhao and Feng, 2005). This might also explain the lower entrapment efficiency of HSPC compared to that of DPPC. Some studies have suggested that naturally occurring or unsaturated phospholipid such as SPC can entrap hydrophobic drugs more efficiently compared to HSPC due to their low gel to liquid-crystalline phase transition temperature $\left(\mathrm{Tm}=-20^{\circ} \mathrm{C}\right)$ (Darwis and Kellaway, 2001, Kan et al., 2011). The liposomes prepared from this type of phospholipid along with cholesterol, are flexible enough to entrap greater proportions of the hydrophobic molecules (Kirby et al., 1980, Senior and Gregoriadis, 1982, Zhang et al., 2005). Thus, liposomes prepared from HSPC liposomes are highly rigid and can limit the penetration of hydrophobic drugs. However, 
DPPC-liposomes have shown high molecular interactions with PX due to their first-order phase transition behaviour (Zhao and Feng, 2004, Zhao and Feng, 2005). It has also been shown that PX interaction with lipid bilayers causes an increase in the surface charge intensity of the liposomes. This property is dependent on high molecular interactions between PX and phospholipids. Negative charge may increase the physical stability of liposomes by minimizing their fusion and aggregation (Kan et al., 2011). Thus, the difference in zeta potential with different PX concentrations may correlate with the different entrapment efficiency using liposome formulations with different lipid compositions. Figure $3 \mathrm{~b}$ and Figure $5 \mathrm{~b}$ clearly represented that higher drug concentrations have conferred more negative surface charge on the DPPC liposomes. The ability of higher drug concentrations to exert that effect on SPC and HSPC vesicles was comparatively less, which correlates well with the entrapment efficiency findings.

\section{Cytotoxicity Studies}

The cytotoxicity of liposomes loaded with a range of paclitaxel concentrations against U87-MG grade IV glioma and SVG-P12 glial cell lines was determined using the MTT assay. Figure 6 shows the effect of liposome formulations on the viability of U87-MG and SVG-P12 cells by plotting the concentrations in log-scale. Cell viabilities of both cell lines with drug-free liposomes increased by increasing concentrations regardless phospholipid type $(\mathrm{P}<0.05)$. This indicates that the preparation methods (i.e. the presence of traces of ethanol and the probe sonication) had no apparent effect on the cytotoxicity of the prepared formulations. In contrast, the cell viability of both U87 and SVG cell 
lines was decreased by approximately $95 \%(\mathrm{P}<0.05)$ when treated with $1500 \mathrm{nM}$ of Paclitaxel.

For U87, Paclitaxel was responsible for the reduction in cell growth by approximately $97 \%$ (viability $=3.24 \% \pm 0.45$ ) with the highest concentration $(1500 \mathrm{nM})(\mathrm{P}<0.05)$. Cytotoxicity of paclitaxel alone was also higher than paclitaxel in liposome formulations by approximately 17\%, $42 \%$ and $3 \%$ when using SPC, HSPC and DPPC respectively $(\mathrm{P}<0.05)$ (Figure 6a). Nevertheless, PX-DPPC-liposomes showed higher cytotoxicity than PXSPC-liposomes and PX-HSPC-liposomes by approximately 16\% and 39\% respectively when using $1500 \mathrm{nM}$ loaded paclitaxel $(\mathrm{P}<0.05)$. High cytotoxicity of PX-DPPC-liposomes might be explained by the higher amount of paclitaxel entrapped in their vesicles compared to that of SPC and HSPC formulations (Figure 5). The reduced cytotoxicity of paclitaxel in liposome formulations as compared to free paclitaxel might be attributed to sustained drug release upon using liposomes (Figure 2S), or because of the nutritional values of phospholipid and cholesterol of liposomes. These results are confirmed by the $\mathrm{IC}_{50}$ of paclitaxel-loaded liposomes and paclitaxel against U87-MG cells (Table 2).

Paclitaxel was responsible for the reduction in SVG cell growth by approximately $91 \%$ (cell viability of $9.38 \% \pm 1.05$ ) at the highest concentration. However, cytotoxicity of paclitaxel was higher than all paclitaxel loaded liposomes $(\mathrm{P}<0.05)$. The results indicate that liposomal formulations of paclitaxel are significantly less toxic $(\mathrm{P}<0.05)$ to glial cells (SVG-P12) than to U87-MG cells by approximately $35 \%, 18 \%$ or $40 \%$ when 
treated with paclitaxel-loaded SPC-liposomes, HSPC-liposomes or DPPCliposomes respectively (Figure 6, Table 2).

The less toxic trend of PX-liposomes formulations may be attributed to the sustained release of paclitaxel from the loaded liposomes contacting the cells and medium (Crosasso et al., 2000, Yang et al., 2007). Furthermore, it has been indicated that incorporating cholesterol in lipid bilayers increased the stability of liposomes and resulted in slower release of paclitaxel (Crosasso et al., 2000). Accordingly, increased $\mathrm{IC}_{50}$ of the PX-liposomes indicates that they were less toxic than paclitaxel (Table 2), which might be attributed to the fact that paclitaxel was retained within the phospholipid bilayers or attached to the surface of liposomes. This suggests that ethanol-based proliposome technology has successfully generated liposomes having sustained release properties by demonstrating a depot effect; part of paclitaxel is stored in the lipid bilayer as a depot, so the larger the depot, the longer the action of paclitaxel (Horowitz et al., 1992, Song et al., 2006). This also indicates that paclitaxel-loaded liposomes having a size of approximately 100 to $200 \mathrm{~nm}$ would remain stable in biological environments; however, further studies should be conducted in vivo to find if a correlation with in vitro findings can be established.

In general, liposomal formulations were also toxic to the SVG-P12 cells, especially for SPC-liposomes, HSPC-liposomes as their $\mathrm{IC}_{50}$ were more than $2000 \mathrm{nM}$ (Table 2). This implies that the liposomal formulations would need more than $2000 \mathrm{nM}$ paclitaxel to kill $50 \%$ of SVG-P12 cells. Thus, $\mathrm{IC}_{50}$ of these liposome formulations was not determined. Paclitaxel has been found to be toxic to a wide variety of human cell lines such as malignant brain 
tumour cells (U87-MG, U373, H80 and D324), breast adenocarcinoma (MCF-7), lung carcinoma (A549), cervical carcinoma (HeLa), colon adenocarcinoma (HT-29), ovarian adenocarcinoma (OVG-1), pancreatic adenocarcinomas (PC-Sh and PC-Zd), and rat brain tumour cell lines (9L and F98) (Liebmann et al., 1993, Cahan et al., 1994). Paclitaxel acts as an inhibitor of cell proliferation in vitro by interfering with the cell cycle development; it works by blocking the cell cycle at $\mathrm{G} 2 / \mathrm{M}$ phase and altering the arrangement of spindle microtubules thereby causing cell death (De Brabander et al., 1981, Jordan et al., 1993, Straubinger et al., 2004). Similar anti-mitotic mechanism, upon treatment with paclitaxel, may have taken place, suggesting the decrease in viability of U87-MG and SVG-P12 cell lines.

SVG-P12 cells showed less sensitivity to paclitaxel and paclitaxel-loaded liposomes than U87-MG cells. This may be due to the reason that the rate at which tumour cells are killed is dependent on their growth curve. Growth curve analysis of the cell lines plays a crucial role in understanding the cell proliferation and effect of anti-tumour agents on them. U87-MG cells reached high confluency (80-90\%) in 2 days while SVG-P12 cells achieved the similar confluency in 4-5 days, for further sub-culturing of the cells. The growth and division of normal cells such as SVG-P12, in tissue culture conditions, are similar to that of U87-MG cells. However, the growth rate of normal cells decreases once they cover the bottom of the culture flask and remain as a monolayer. Growth inhibition may be caused by the exhaustion of growth factors in the medium. On the other hand, glioma cells continue to grow until they overlap with surrounding cells and form clumps. This may be 
because they are unresponsive to the signals that cause the cessation of growth and division of their normal counterparts. This might explain the rapid decrease in the viability of U87-MG cells as compared to that of SVG-P12 cells when treated with paclitaxel and liposome formulations (Karp, 2010). Drug-free formulations did not show any toxic effect on glioma as well as normal glial cell lines. Similarly, studies have shown that drug-free liposomes displayed non-toxic effect or effect equal to that of negative control on both cancer and normal cells in vitro (Al-Suwayeh et al., 1996, Graeser et al., 2009). This may be due to that liposomes are prepared from naturally occurring materials such as phospholipids and cholesterol which are major constituents of biological membranes essential for cellular functions. Phosphatidylcholine forms a major component of the cell membranes and are found in the exoplasmic membrane leaflets. In fact, liposome vesicles might enhance the efficacy of the drugs by binding to the cells and releasing the therapeutic molecules in a sustained manner (Lasic, 1995, Al-Suwayeh et al., 1996, Liu et al., 2013).

\section{Conclusions}

In this study, paclitaxel-loaded liposomes were prepared using ethanol-based proliposome technology. The influence of lipid composition (SPC:Chol, HSPC:Chol and DPPC:Chol in equimolar ratio) on the physicochemical properties of formulations, entrapment efficiency of paclitaxel in the liposomes and the cytotoxicity of the formulations were investigated. MLVs generated as a result of hydrating the proliposomes were successfully fragmented into nano-sized liposomes (100-200 nm) using probe-sonication for $10 \mathrm{~min}$. The PI of all the formulations was below 0.3 , indicating that sonication time selected was appropriate to form homogenous liposomes. 
DPPC-liposomes had more intense surface charge upon using higher paclitaxel concentrations and the $\mathrm{pH}$ of DPPC liposomes was found to be the closest to the $\mathrm{pH}$ of physiological fluids ( $\mathrm{pH}$ 7.4) making DPPC liposomes potentially highly appropriate vehicles for the anticancer drug paclitaxel. In addition, entrapment of paclitaxel in DPPC liposomes was generally higher than that in SPC or HSPC vesicles.

The cytotoxicity of paclitaxel-loaded liposomes against U87-MG (grade IV glioma) and SVG-P12 glial cell lines was determined using MTT assay. It was observed that paclitaxel alone was more toxic to U87-MG and SVG-P12 cells than paclitaxel in liposome formulations. PX-DPPC-liposomes showed higher cytotoxicity than PX-SPC and PX-HSPC formulations. The results were in correlation with the entrapment efficiency findings. Noteworthy, all liposomal formulations of PX had higher selective cytotoxicity to the malignant U87 cells compared to PX alone. Overall, this study has demonstrated that ethanol-based proliposomes, generating vesicles with a size of approximately 100 to $200 \mathrm{~nm}$, made of DPPC and cholesterol may have a great potential to be used as an anticancer carrier. The results suggest that liposomes prepared by ethanol-based proliposome technology are able to act as potential nanocarriers of poorly water-soluble anticancer drugs (e.g. paclitaxel). However, comprehensive stability studies of such liposomes in several storage conditions are currently under investigation. Ethanol-based proliposome technology will be of great interest for the development of delivery systems to overcome challenging biological barriers such as Blood Brian Barrier (BBB). Such liposomal systems may comprise phospholipids attached to targeting moieties (e.g. folate), long circulating moieties such as 
polyethylene glycol chains or/and even permeability enhancers such fatty acid chains. These strategies will be part of future investigations.

\section{Acknowledgements}

We would like to thank Lipoid, Switzerland for providing the phospholipids. We also thank Mr David McCarthy, Microscopy Unit, UCL-School of Pharmacy for the TEM images.

\section{References}

Al-Suwayeh, S.A., Tebbett, I.R., Wielbo, D. \& Brazeau, G.A., 1996. In vitro-in vivo myotoxicity of intramuscular liposomal formulations. Pharm Res, 13, 1384-8.

Balasubramanian, S.V. \& Straubinger, R.M., 1994. Taxol-lipid interactions: Taxoldependent effects on the physical properties of model membranes. Biochemistry, 33, 8941-8947.

Cabanes, A., Briggs, K.E., Gokhale, P.C., Treat, J.A. \& Rahman, A., 1998. Comparative in vivo studies with paclitaxel and liposome-encapsulated paclitaxel. Int J Oncol, 12, 1035-40.

Cahan, M.A., Walter, K.A., Colvin, O.M. \& Brem, H., 1994. Cytotoxicity of taxol in vitro against human and rat malignant brain tumors. Cancer Chemother Pharmacol, 33, 441-4.

Crosasso, P., Ceruti, M., Brusa, P., Arpicco, S., Dosio, F. \& Cattel, L., 2000. Preparation, characterization and properties of sterically stabilized paclitaxel-containing liposomes. J Control Rel, 63, 19-30.

Darwis, Y. \& Kellaway, I.W., 2001. Nebulisation of rehydrated freeze-dried beclomethasone dipropionate liposomes. Int J Pharm, 215, 113-21.

De Brabander, M., Geuens, G., Nuydens, R., Willebrords, R. \& De Mey, J., 1981. Taxol induces the assembly of free microtubules in living cells and blocks the organizing capacity of the centrosomes and kinetochores. Proc Natl Acad Sci U S A, 78, 5608-612.

Deo, M.R., Sant, V.P., Parekh, S.R., Khopade, A.J. \& Banakar, U.V., 1997. Proliposomebased transdermal delivery of levonorgestrel. J Biomater Appl, 12, 77-88.

Elhissi, A., Hidayat, K., Phoenix, D.A., Mwesigwa, E., Crean, S., Ahmed, W., Faheem, A. \& Taylor, K.M., 2013. Air-jet and vibrating-mesh nebulization of niosomes generated using a particulate-based proniosome technology. Int J Pharm, 444, 193-9.

Elhissi, A.M., Karnam, K.K., Danesh-Azari, M.R., Gill, H.S. \& Taylor, K.M., 2006. Formulations generated from ethanol-based proliposomes for delivery via medical nebulizers. J Pharm Pharmacol, 58, 887-94.

Fetterly, G.J. \& Straubinger, R.M., 2003. Pharmacokinetics of paclitaxel-containing liposomes in rats. AAPS PharmSci, 5, E32.

Gala, R.P., Khan, I., Elhissi, A.M. \& Alhnan, M.A., 2015. A comprehensive production method of self-cryoprotected nano-liposome powders. Int J Pharm, 486, 153-158. 
Garber, K., 2004. Improved paclitaxel formulation hints at new chemotherapy approach. J Natl Cancer Inst, 96, 90-1.

Graeser, R., Bornmann, C., Esser, N., Ziroli, V., Jantscheff, P., Unger, C., Hopt, U.T., Schaechtele, C., Von Dobschuetz, E. \& Massing, U., 2009. Antimetastatic effects of liposomal gemcitabine and empty liposomes in an orthotopic mouse model of pancreatic cancer. Pancreas, 38, 330-7.

Grit, M., De Smidt, J.H., Struijke, A. \& Crommelin, D.J.A., 1989. Hydrolysis of phosphatidylcholine in aqueous liposome dispersions. Int J Pharm, 50, 1-6.

Horowitz, A.T., Barenholz, Y. \& Gabizon, A.A., 1992. In vitro cytotoxicity of liposomeencapsulated doxorubicin: dependence on liposome composition and drug release. Biochimica et Biophysica Acta (BBA) - Biomembranes, 1109, 203-209.

Howard, F. \& Levin, I., 2010. Lipid vesicle aggregation induced by cooling. Int J Mol Sci, 11, 754-761.

Jordan, M.A., Toso, R.J., Thrower, D. \& Wilson, L., 1993. Mechanism of mitotic block and inhibition of cell proliferation by taxol at low concentrations. Proc Natl Acad Sci U S A, 90, 9552-6.

Kadam, A.N., Najlah, M., Wan, K.-W., Ahmed, W., Crean, S.J., Phoenix, D.A., Taylor, K.M.G. \& Elhissi, A.M.A., 2014. Stability of parenteral nanoemulsions loaded with paclitaxel: the influence of lipid phase composition, drug concentration and storage temperature. Pharm Dev Technol, 19, 999-1004.

Kan, P., Tsao, C.W., Wang, A.J., Su, W.C. \& Liang, H.F., 2011. A liposomal formulation able to incorporate a high content of paclitaxel and exert promising anticancer effect. J Drug Deliv 2011.

Karp, G., 2010. Cell and Molecular Biology: concepts and experiments, 6 ed. New York: John Wiley \& Sons.

Kensil, C.R. \& Dennis, E.A., 1981. Alkaline hydrolysis of phospholipids in model membranes and the dependence on their state of aggregation. Biochemistry, 20, 6079-85.

Kirby, C., Clarke, J. \& Gregoriadis, G., 1980. Effect of the cholesterol content of small unilamellar liposomes on their stability in vivo and in vitro. Biochem J, 186, 5918.

Konno, T., Watanabe, J. \& Ishihara, K., 2003. Enhanced solubility of paclitaxel using water-soluble and biocompatible 2-methacryloyloxyethyl phosphorylcholine polymers. J Biomed Mater Res A, 65, 209-14.

Koudelka, Š. \& Turánek, J., 2012. Liposomal paclitaxel formulations. J Control Release, $163,322-334$.

Kumar, R., Gupta, R.B. \& Betageri, G.V., 2001. Formulation, characterization, and in vitro release of glyburide from proliposomal beads. Drug Delivery, 8, 25-27.

Lasic, D.D., 1995. Applications of Liposomes. In R. Lipowsky \& E. Sackmann (eds.) Handbook of Biological Physics. California, USA: Elsevier Science B.V, 491519.

Liebmann, J.E., Cook, J.A., Lipschultz, C., Teague, D., Fisher, J. \& Mitchell, J.B., 1993. Cytotoxic studies of paclitaxel (Taxol) in human tumour cell lines. Br J Cancer, 68, 1104-9.

Liu, Y., Ji, M., Wong, M.K., Joo, K.-I. \& Wang, P., 2013. Enhanced therapeutic efficacy of iRGD-conjugated crosslinked multilayer liposomes for drug delivery. Biomed Res Int, 2013, 11.

Ofir, E., Oren, Y. \& Adin, A., 2007. Electroflocculation: the effect of zeta-potential on particle size. Desalination, 204, 33-38.

Panchagnula, R., 1998. Pharmaceutical aspects of paclitaxel. Int J Pharm, 172, 1-15. 
Payne, N.I., Browning, I. \& Hynes, C.A., 1986a. Characterization of proliposomes. $J$ Pharm Sci, 75, 330-3.

Payne, N.I., Timmins, P., Ambrose, C.V., Ward, M.D. \& Ridgway, F., 1986b. Proliposomes: a novel solution to an old problem. J Pharm Sci, 75, 325-9.

Perrett, S., Golding, M. \& Williams, W.P., 1991. A simple method for the preparation of liposomes for pharmaceutical applications: characterization of the liposomes. $J$ Pharm Pharmacol, 43, 154-61.

Rowinsky, E.K. \& Donehower, R.C., 1995. Paclitaxel (taxol). N Engl J Med, 332, 100414.

Senior, J. \& Gregoriadis, G., 1982. Stability of small unilamellar liposomes in serum and clearance from the circulation: The effect of the phospholipid and cholesterol components. Life Sciences, 30, 2123-2136.

Sharma, A., Mayhew, E. \& Straubinger, R.M., 1993. Antitumor effect of taxol-containing liposomes in a taxol-resistant murine tumor model. Cancer Res, 53, 5877-81.

Singla, A.K., Garg, A. \& Aggarwal, D., 2002. Paclitaxel and its formulations. Int J Pharm, 235, 179-192.

Song, H., Zhang, J., Han, Z., Zhang, X., Li, Z., Zhang, L., Fu, M., Lin, C. \& Ma, J., 2006. Pharmacokinetic and cytotoxic studies of pegylated liposomal daunorubicin. Cancer Chemother Pharmacol, 57, 591-598.

Straubinger, R.M., Arnold, R.D., Zhou, R., Mazurchuk, R. \& Slack, J.E., 2004. Antivascular and antitumor activities of liposome-associated drugs. Anticancer Res, 24, 397-404.

Turánek, J., Zaluska, D. \& Neca, J., 1997. Linkup of a fast protein liquid chromatography system with a stirred thermostated cell for sterile preparation of liposomes by the proliposome-liposome method: application to encapsulation of antibiotics, synthetic peptide immunomodulators, and a photosensitizer. Anal Biochem, 249, $131-9$.

Wang, X., Song, L., Li, N., Qiu, Z., Zhou, S., Li, C., Zhao, J., Song, H. \& Chen, X., 2013. Pharmacokinetics and biodistribution study of paclitaxel liposome in SpragueDawley rats and Beagle dogs by liquid chromatography-tandem mass spectrometry. Drug Res (Stuttg), 63, 603-6.

Wani, M.C., Taylor, H.L., Wall, M.E., Coggon, P. \& Mcphail, A.T., 1971. Plant antitumor agents. VI. Isolation and structure of taxol, a novel antileukemic and antitumor agent from Taxus brevifolia. J Am Chem Soc, 93, 2325-2327.

Yang, T., Cui, F.-D., Choi, M.-K., Cho, J.-W., Chung, S.-J., Shim, C.-K. \& Kim, D.-D., 2007. Enhanced solubility and stability of PEGylated liposomal paclitaxel: In vitro and in vivo evaluation. Int J Pharm, 338, 317-326.

Yoshizawa, Y., Ogawara, K., Kimura, T. \& Higaki, K., 2014. A novel approach to overcome multidrug resistance: utilization of P-gp mediated efflux of paclitaxel to attack neighboring vascular endothelial cells in tumors. Eur J Pharm Sci, 62, 274-80.

Zhang, J.A., Anyarambhatla, G., Ma, L., Ugwu, S., Xuan, T., Sardone, T. \& Ahmad, I., 2005. Development and characterization of a novel Cremophor EL free liposomebased paclitaxel (LEP-ETU) formulation. Eur J Pharm Biopharm, 59, 177-87.

Zhao, L. \& Feng, S.S., 2004. Effects of lipid chain length on molecular interactions between paclitaxel and phospholipid within model biomembranes. $J$ Colloid Interface Sci, 274, 55-68.

Zhao, L. \& Feng, S.S., 2005. Effects of lipid chain unsaturation and headgroup type on molecular interactions between paclitaxel and phospholipid within model biomembrane. J Colloid Interface Sci, 285, 326-335. 
Zhao, L., Feng, S.S., Kocherginsky, N. \& Kostetski, I., 2007. DSC and EPR investigations on effects of cholesterol component on molecular interactions between paclitaxel and phospholipid within lipid bilayer membrane. Int J Pharm, $338,258-66$.

Zhou, R., Mazurchuk, R.V., Tamburlin, J.H., Harrold, J.M., Mager, D.E. \& Straubinger, R.M., 2010. Differential pharmacodynamic effects of paclitaxel formulations in an intracranial rat brain tumor model. J Pharmacol Exp Ther, 332, 479-88. 
Table 1. Lipids and paclitaxel contents of liposomal formations.

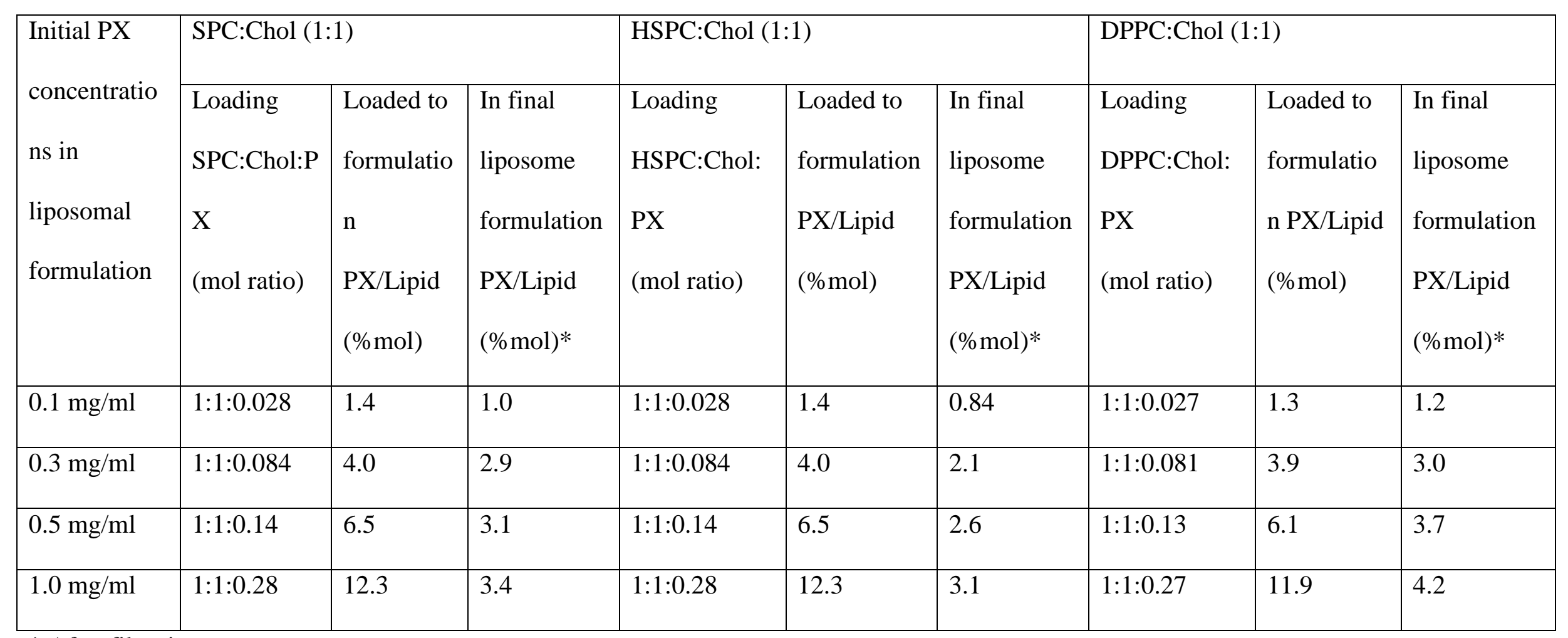

* After filtration 
Table 2. IC 50 (nM of paclitaxel-loaded liposomes and paclitaxel SVG-P12 and U87MG cells. $(n=3 \pm S D)$

\begin{tabular}{|l|l|l|}
\hline Formulation & IC50 Value $(\mathrm{nM}) \pm$ SD for & IC 50 Value $(\mathrm{nM}) \pm$ SD for \\
& SVG-P12 cells & U87-MG cells \\
\hline Paclitaxel & $44.3 \pm 9.2$ & $23.0 \pm 6.1$ \\
\hline DPPC+paclitaxel & $936.7 \pm 57.8$ & $61.3 \pm 7.9$ \\
\hline SPC+paclitaxel & $>2000$ & $245.2 \pm 21.4$ \\
\hline HSPC+paclitaxel & $>2000$ & $1030.1 \pm 123.6$ \\
\hline
\end{tabular}


(a) $\square$ Drug-free liposomes $\square 0.1 \mathrm{mg} / \mathrm{ml} \varpi 03 . \mathrm{mg} / \mathrm{ml} \varpi 0.5 \mathrm{mg} / \mathrm{ml} \square 1 \mathrm{mg} / \mathrm{ml}$

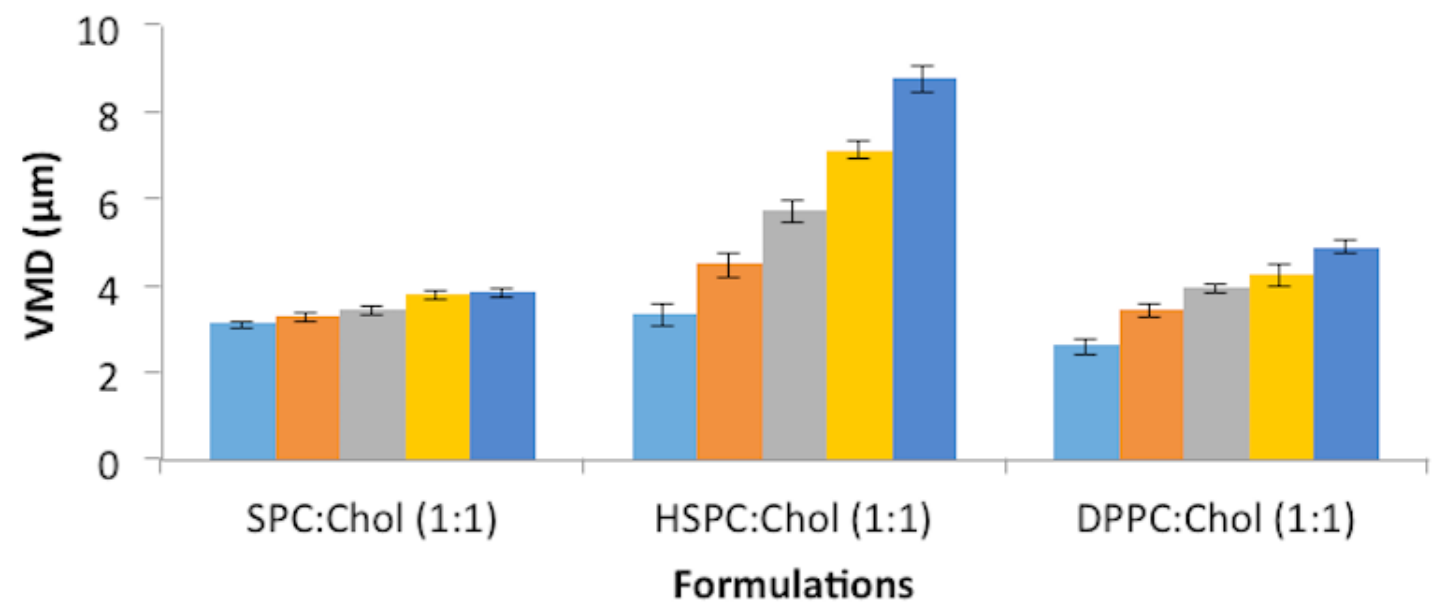

(b) $\square$ Drug-free liposomes $\square 0.1 \mathrm{mg} / \mathrm{ml} \varpi 0.3 \mathrm{mg} / \mathrm{ml} \varpi 0.5 \mathrm{mg} / \mathrm{ml} \square 1.0 \mathrm{mg} / \mathrm{ml}$

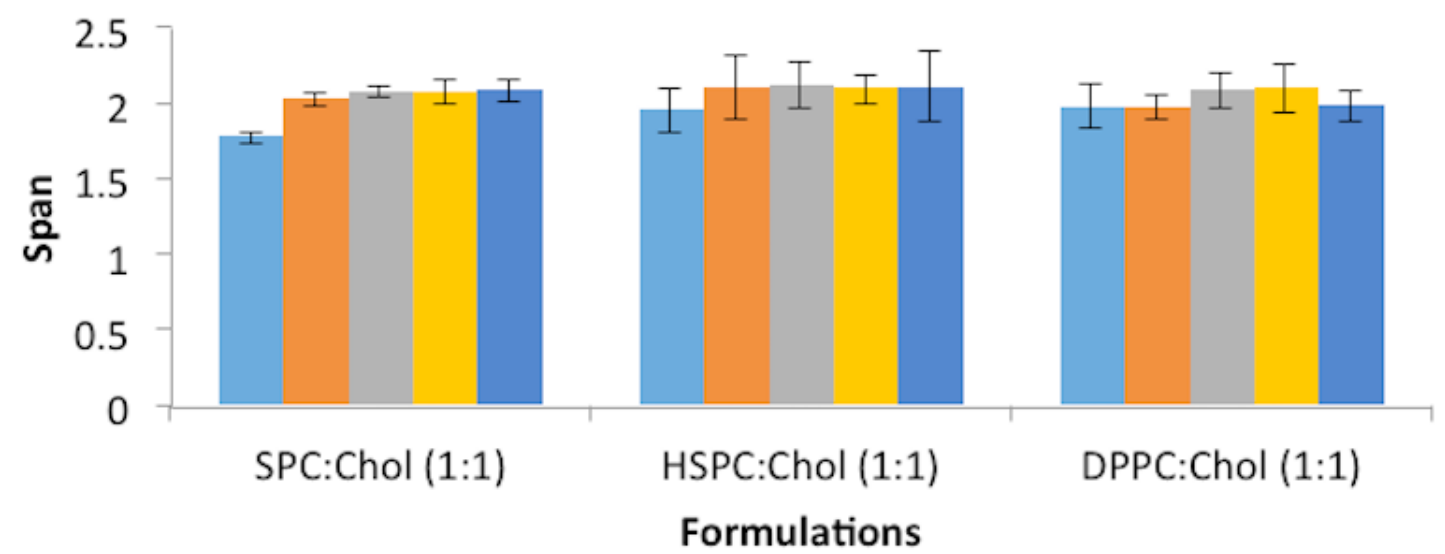

Figure 1. (a) Volume median diameter (VMD) and (b) Size distribution (Span) of liposomes generated from ethanol-based proliposome formulations with a range of paclitaxel concentrations $(n=3 \pm S D)$. 
(a)

Drug-free liposomes $\square 0.1 \mathrm{mg} / \mathrm{ml}=0.3 \mathrm{mg} / \mathrm{ml}=0.5 \mathrm{mg} / \mathrm{ml} \square 1.0 \mathrm{mg} / \mathrm{ml}$

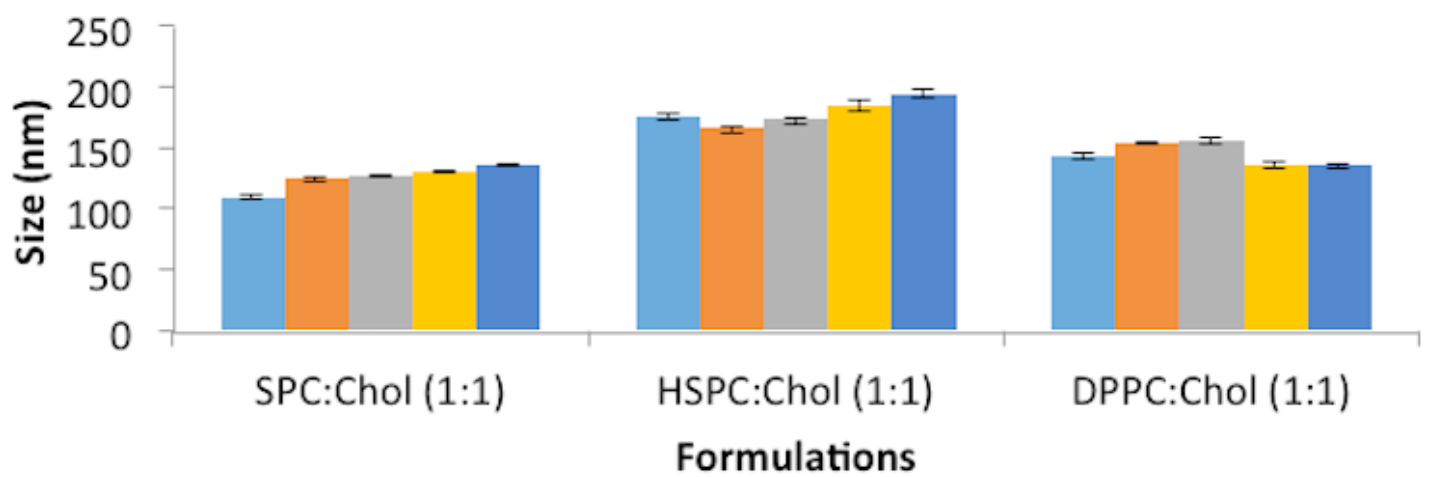

(b)

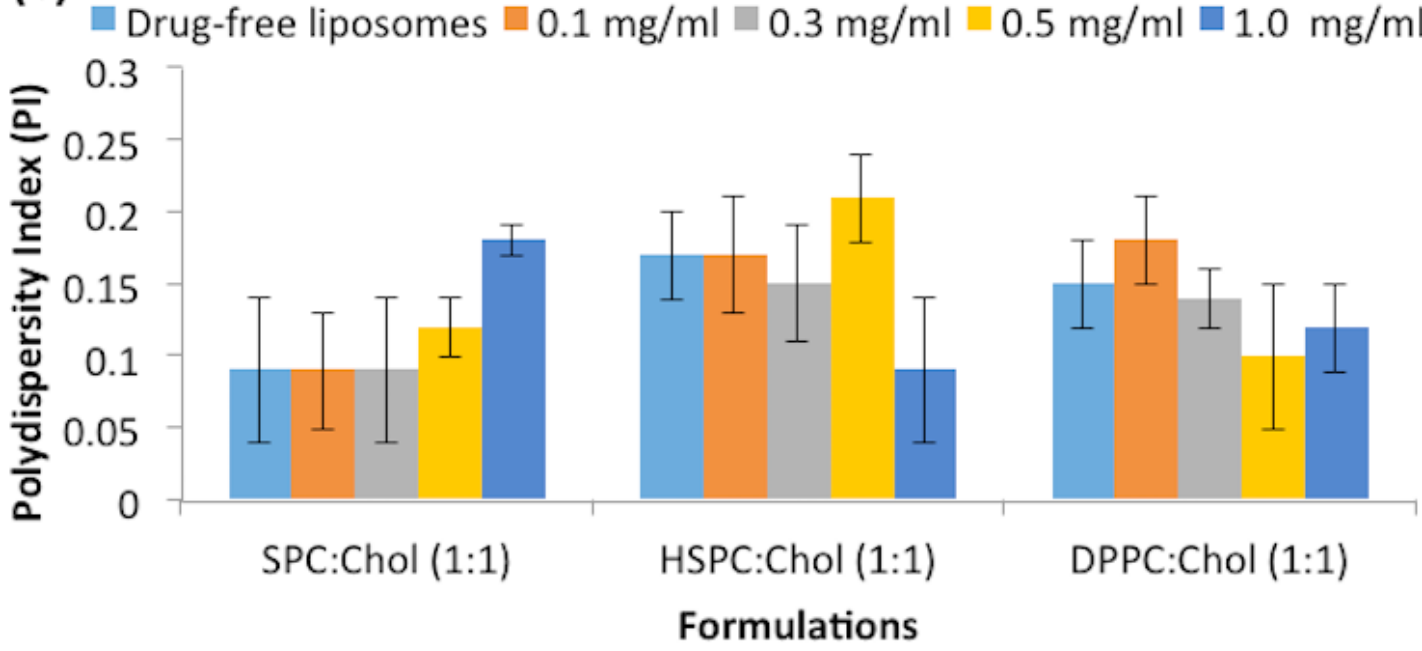

Figure 2. (a) Size (Zaverage) of liposomes after probe sonication, (b) PI of liposomes after probe sonication with a range of paclitaxel concentrations $(n=3 \pm S D)$. 
(a) $\square$ Drug-free liposomes $\square 0.1 \mathrm{mg} / \mathrm{ml} \square 0.3 \mathrm{mg} / \mathrm{ml} \square 0.5 \mathrm{mg} / \mathrm{ml} \square 1.0 \mathrm{mg} / \mathrm{ml}$

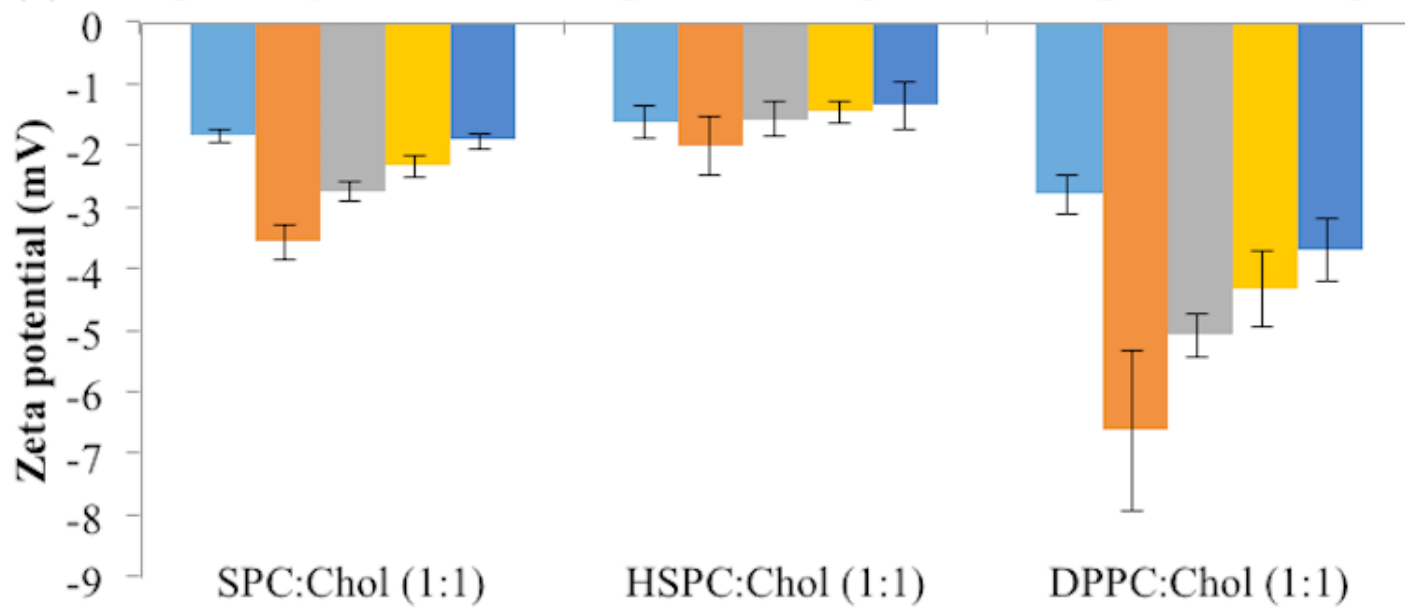

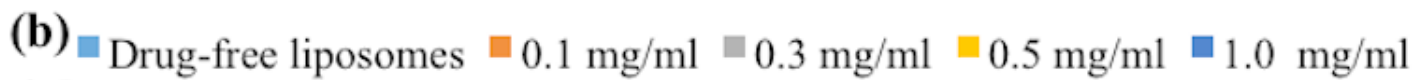

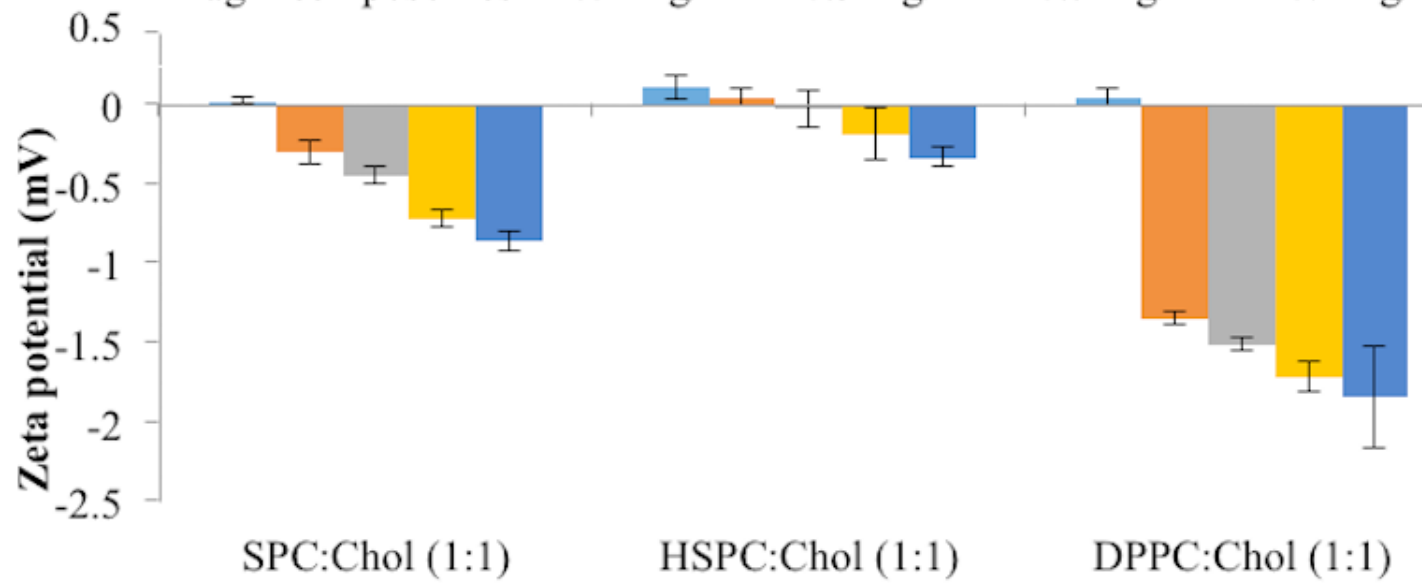

Figure 3. Zeta potential of liposomes (a) before probe sonication and (b) after probe sonication with a range of paclitaxel concentrations $(n=3 \pm S D)$ 
$\square$ Drug-free liposomes $\square 0.1 \mathrm{mg} / \mathrm{ml} \square 0.3 \mathrm{mg} / \mathrm{ml} \square 0.5 \mathrm{mg} / \mathrm{ml} \square 1.0 \mathrm{mg} / \mathrm{ml}$

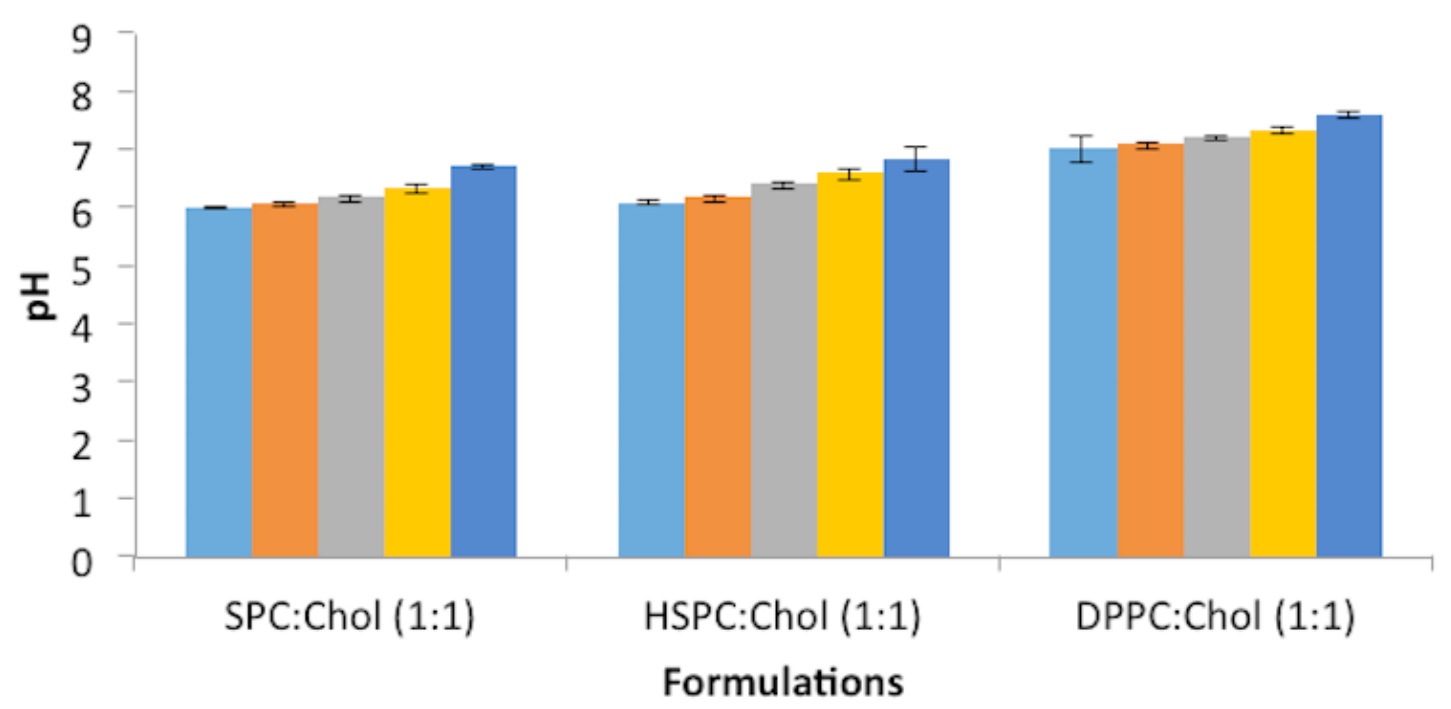

Figure 4. $\mathrm{pH}$ of liposomes after probe sonication with a range of paclitaxel concentrations $(n=3 \pm S D)$. 
(a) $\quad 0.1 \mathrm{mg} / \mathrm{ml} \quad 0.3 \mathrm{mg} / \mathrm{ml} \quad \square .5 \mathrm{mg} / \mathrm{ml} \quad \square 1.0 \mathrm{mg} / \mathrm{ml}$
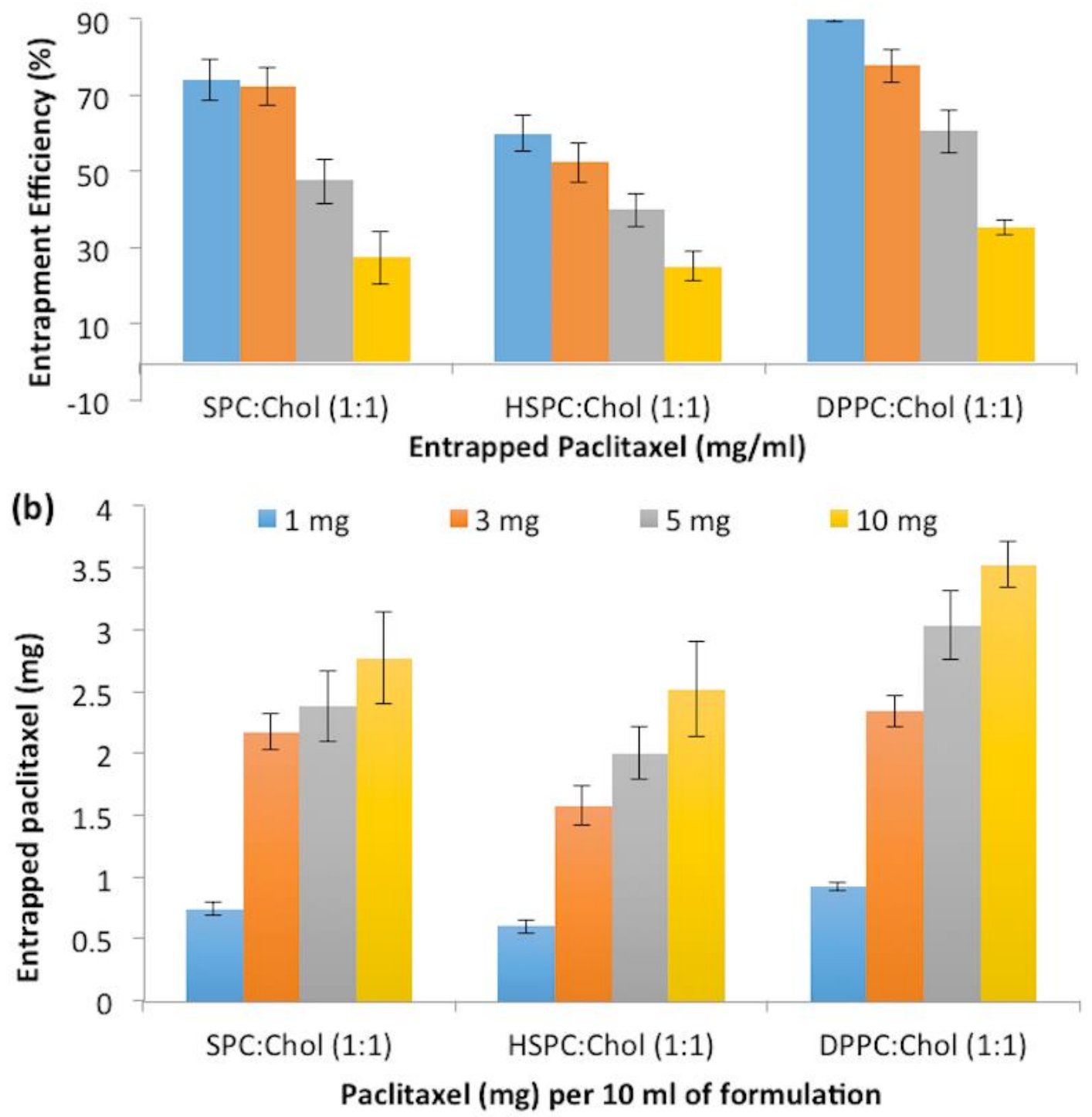

Figure 5. (a) Entrapment efficiency of liposomes and (b) The amount of paclitaxel entrapped per $10 \mathrm{ml}$ of formulation $(\mathrm{N}=3 \pm \mathrm{SD})$. 


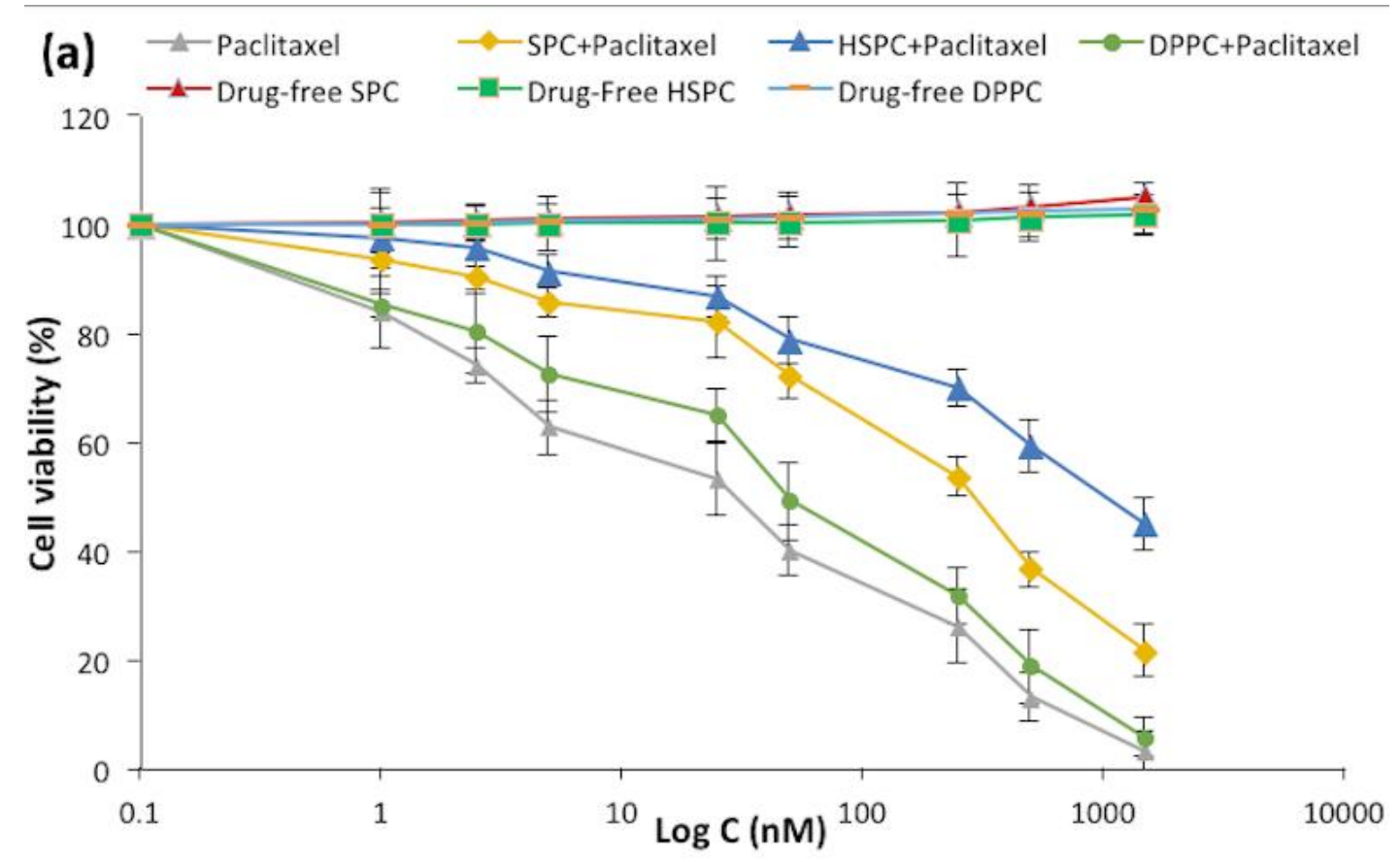

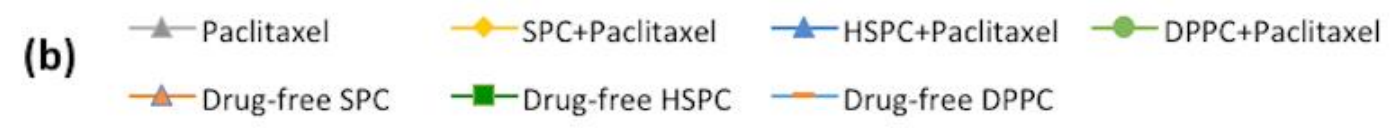

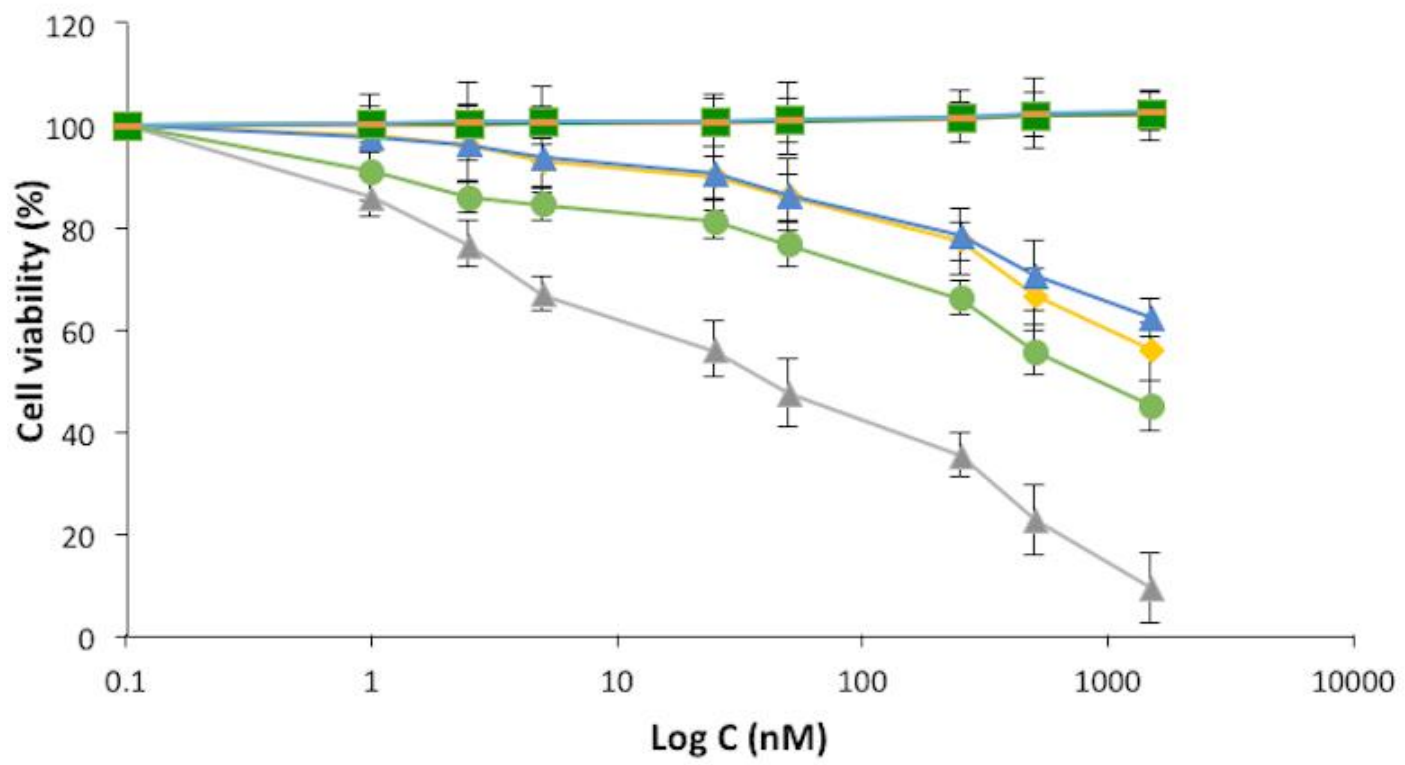

Figure 6. Viability of (a) U87-MG and (b) SVG-P12 cell line tested with increasing concentrations of different formulations in 96-well plates. $(n=18, N=3 \pm S D)$ 
Figure captions

Figure 1. (a) Volume median diameter (VMD) and (b) Size distribution (Span) of liposomes generated from ethanol-based proliposome formulations with a range of paclitaxel concentrations ( $\mathrm{n}=3 \pm \mathrm{SD})$.

Figure 2. (a) Size (Zaverage) of liposomes after probe sonication, (b) PI of liposomes after probe sonication with a range of paclitaxel concentrations $(n=3 \pm S D)$.

Figure 3. Zeta potential of liposomes (a) before probe sonication and (b) after probe sonication with a range of paclitaxel concentrations $(n=3 \pm S D)$

Figure 4. $\mathrm{pH}$ of liposomes after probe sonication with a range of paclitaxel concentrations $(n=3 \pm S D)$.

Figure 5. (a) Entrapment efficiency of liposomes and (b) The amount of paclitaxel entrapped per $10 \mathrm{ml}$ of formulation $(\mathrm{N}=3 \pm \mathrm{SD})$.

Figure 6. Viability of (a) U87-MG and (b) SVG-P12 cell line tested with increasing concentrations of different formulations in 96-well plates. $(n=18, N=3 \pm S D)$ 